\title{
Rancang Bangun Sistem Informasi Perusahaan untuk Mendukung Rekrutmen Karyawan Pada PT.Isargas
}

\author{
Khaidir Fahram \\ ${ }^{1}$ Program Studi Teknik Informatika STTIKOM Insan Unggul Cilegon \\ E-mail: ${ }^{* 1}$ khaidir@gmail.com
}

\begin{abstract}
Abstrak
Suatu perusahaan tentunya membutuhkan informasi yang cepat dan akurat, salah satunya adalah informasi tentang rekrutmen karyawan. PT Isargas adalah perusahaan swasta yang bergerak di bidang transmisi dan distribusi gas bumi. Saat ini dalam proses rekrutmen karyawan masih sangat manual dengan datang langsung ke perusahaan untuk melihat papan madding yang berisi informasi lowongan kerja yang tersedia. Dan proses pengolahan data menggunakan aplikasi Ms. Excel. Dimana membutuhkan waktu dan biaya yang tidak sedikit. Dalam hal ini penulis melakukan beberapa penelitian pada perusahaan dengan menggunakan beberapa metode diantaranya menggunakan metode pengumpulan data, metode analisis, metode perancangan sistem, dan metode pengujian. Dimana metode pengumpulan datanya berupa observasi, wawancara, studi pustaka seperti observasi, bertanya kepada narasumber dan pencarian buku. Metode analisis yang digunakan meliputi analisis SWOT, metode perancangan sistem dimana penulisan sistem menggunakan UML (Unified Modeling Language), dan metode pengujian menggunakan pengujian blackbox. Dalam hal ini peneliti mempunyai beberapa tujuan dalam melakukan penelitian ini, diantaranya untuk dapat mengetahui sistem yang sedang berjalan di perusahaan, meminimalisir kesalahan yang sering terjadi akibat penggunaan sistem manual, dan merancang sistem rekrutmen dari manual ke sistem, sehingga dalam penelitian ini menghasilkan manfaat seperti memberikan solusi mengenai kebutuhan sistem informasi dalam pengambilan keputusan yang dapat berjalan dengan lancar dan akurat, memudahkan proses pengambilan keputusan mengenail rekrutmen karyawan, dan menghasilkan sistem rekrutmen karyawan berbasis web.
\end{abstract}

Kata Kunci: Rekrutmen, Rekrutmen Karyawan, lowongan kerja

\begin{abstract}
A company certainly needs fast and accurate information, one of which is information about employee recruitment. PT Isargas is a private company engaged in the transmission and distribution of natural gas. Currently, the employee recruitment process is still very manual, by coming directly to the company to see a board that contains information on available job vacancies. And data processing using Ms. application. Excel. Which requires a lot of time and money. In this case the authors conducted several studies on the company using several methods including using data collection methods, analysis methods, system design methods, and testing methods. Where the data collection methods are in the form of observations, interviews, literature studies such as observation, asking sources and searching for books. The analysis method used includes SWOT analysis, system design methods where the writing of the system uses UML (Unified Modeling Language), and the testing method uses blackbox testing. In this case the researcher has several objectives in conducting this research, including being able to find out which system is currently running in the company, minimizing errors that often occur due to the use of manual systems, and designing a recruitment system from manual to system,
\end{abstract}


so that in this study it produces benefits such as providing solutions regarding the need for information systems in decision making that can run smoothly and accurately, facilitate the decision-making process regarding employee recruitment, and produce a web-based employee recruitment system.

Keywords: Recruitment, Employee Recruitment, job vacancies.

\section{PENDAHULUAN}

Dengan perkembangan ilmu teknologi informasi yang berkembang pesat saat ini maka sangat diperlukan sumber daya manusia (SDM) yang berkualitas yang dapat mengikuti arus globalisasi yang saat ini kental dengan ilmu teknologi. Dalam mencari lowongan kerja, pelamar biasanya masih menggunakan cara konvensional yaitu dengan mengunjungi perusahaan untuk melihat papan pengumuman (bulletin board). Untuk mendapatkan SDM yang berkualitas, proses perekrutan karyawan baru sangat ketat. Calon pekerja yang akan melamar pekerjaan tentunya harus sesuai dengan kriteria yang diinginkan dan memiliki kompetensi yang kuat di bidang yang berlaku di perusahaan. Rekrutmen di PT. Isargas sudah terkomputerisasi yaitu menggunakan MS Excel. Hal ini berakibat menumpuknya berkas pelamar dan keterlambatan mendapatkan informasi data calon kepegawaian, serta butuh waktu lebih lama untuk mengumpulkan data pelamar. Oleh karena itu, diperlukan sistem rekrutmen dengan memanfaatkan internet yang saat ini menjadi salah satu media informasi. Dimana aplikasi rekrutmen dapat menyimpan data curriculum vitae calon tenaga kerja secara lebih rapi dan terstruktur dengan baik, sehingga nantinya dapat memberikan rekomendasi kepada Bagian Sumber Daya Manusia PT. Isargas, untuk menerima beberapa calon tenaga kerja dengan nilai kumulatif tertinggi untuk seleksi ke tahap selanjutnya.

\section{TINJAUAN PUSTAKA}

\section{Rekrutmen}

Bairizki (2020:187), Rekrutmen merupakan proses mendapatkan sejumlah tenaga kerja potensial dari berbagai sumber untuk ditempatkan pada posisi yang tersedia di suatu organisasi atau perusahaan. [1]

\section{Karyawan}

Zamzami dkk (2021:52), Karyawan merupakan unsur penting dalam setiap pengendalian internal. Jika perusahaan mempunyai karyawan yang kompeten dan jujur, maka unsur pengendalian internal yang lain dapt dikurangi sampai batas minimum dan perusahaan tteap mampu menghasilkan pertanggungjawaban keuangan yang handal. Pengendalian internal yang baik tidak akan dapat menghasilkan informasi keuangan yang andal jika dilaksanakan oleh karyawan yang tidak kompeten dan jujur.[2]

\section{Sumber Daya Manusia}

Siregar dkk (2020:140), SDM merupakan faktor yang mempengaruhi perkembangan suatu perusahaan maupun dalam suatu organisasi sehingga dituntut memiliki sumber daya manusia yang berkualitas dan cerdas, sehingga mampu menjadi energi bagi organisasi atau perusahaan yang menginginkan sumber daya manusia (SDM). [3]

\section{LITERATUR REVIEW}

1. Widyastuti dan Sulistyorini (2020)[4], dalam penelitiannya mengenai E-Recruitment Karyawan Berbasis Web Sebagai Upaya Meningkatkan Efisiensi Seleksi Penerimaan Karyawan Baru. Hasil yang didapat dari penelitian tersebut Menghasilkan program aplikasi 
rekrutmen berbasis web interaktif dengan metode registrasi online yang memudahkan calon karyawan untuk melamar pekerjaan, dan sistem memudahkan pencarian data calon karyawan yang diterima atau data calon karyawan yang diterima dan tidak diterima.

2. Yanto dkk (2018)[5], dalam penelitiannya mengenai Sistem Informasi E-Recruitment Karyawan Berbasis Web Pada PT. Jasa Swadayautama (Jayatama). Hasil yang didapat dari penelitian tersebut Menghasilkan sistem rekrutmen karyawan secara online memudahkan bagian Personalia dalam membaca data pelamar, dan menghemat ruang dan waktu untuk penyimpanan data, mempermudah pencarian, mengurangi biaya yang dikeluarkan perusahaan untuk proses rekrutmen pegawai.

3. Hapsari dan Purwatiningtyas (2017)[6], dalam penelitiannya mengenai Sistem Informasi Penerimaan Karyawan Berbasis Web Pada Brt Trans Semarang. Hasil yang didapat dari penelitian tersebut Sistem yang dibuat mampu memantau dan menampung data dengan baik, hal ini berdampak pada minimnya data yang hilang dan memudahkan dalam pencarian data calon pegawai yang telah diterima atau datanya calon karyawan yang tidak diterima

\section{METODE PENELITIAN}

Dalam menganalisis metode yang digunakan analisis SWOT yang berisikan 2 faktor yaitu faktor internal meliputi Strength (Kekuatan) dan Weakness (Kelemahan) sedangkan untuk faktor eksternal yang akan dihadapi oleh perusahaan meliputi Opportunities (Peluang) dan Threat (Ancaman). Berikut adalah tabel matriks identifikasi metode SWOT.

Tabel 1. Metode SWOT

\begin{tabular}{|c|c|}
\hline Kekuatan (Strenghts) & Kelemahan (Weakness) \\
\hline $\begin{array}{l}\text { 1. Memudahkan pelamar } \\
\text { mendapatkan informasi } \\
\text { 2. Melakukan pelayanan } \\
\text { dalam menangani rekrutmen } \\
\text { dengan baik }\end{array}$ & $\begin{array}{l}\text { 1. Pelamar datang ke } \\
\text { perusahaan untuk } \\
\text { melampirkan berkas } \\
\text { surat lamaran } \\
\text { 2. Area penyimpanan data } \\
\text { kurang efektif sehingga } \\
\text { data sering hilang }\end{array}$ \\
\hline Pelu & n (Threats) \\
\hline $\begin{array}{l}\text { 1. Pengguna waktu yang lebih } \\
\text { efisien } \\
\text { 2. Mengembangkan pengguna } \\
\text { teknologi } \\
\text { 3. mengurangi ketenangan } \\
\text { kerja }\end{array}$ & $\begin{array}{l}\text { 1. Teknologi informasi } \\
\text { berkembang sangat pesat } \\
\text { 2. Penipuan dalam } \\
\text { lowongan kerja yang } \\
\text { merugikan pelamar }\end{array}$ \\
\hline
\end{tabular}




\section{HASIL DAN PEMBAHASAN}

\section{Usecase Diagram}

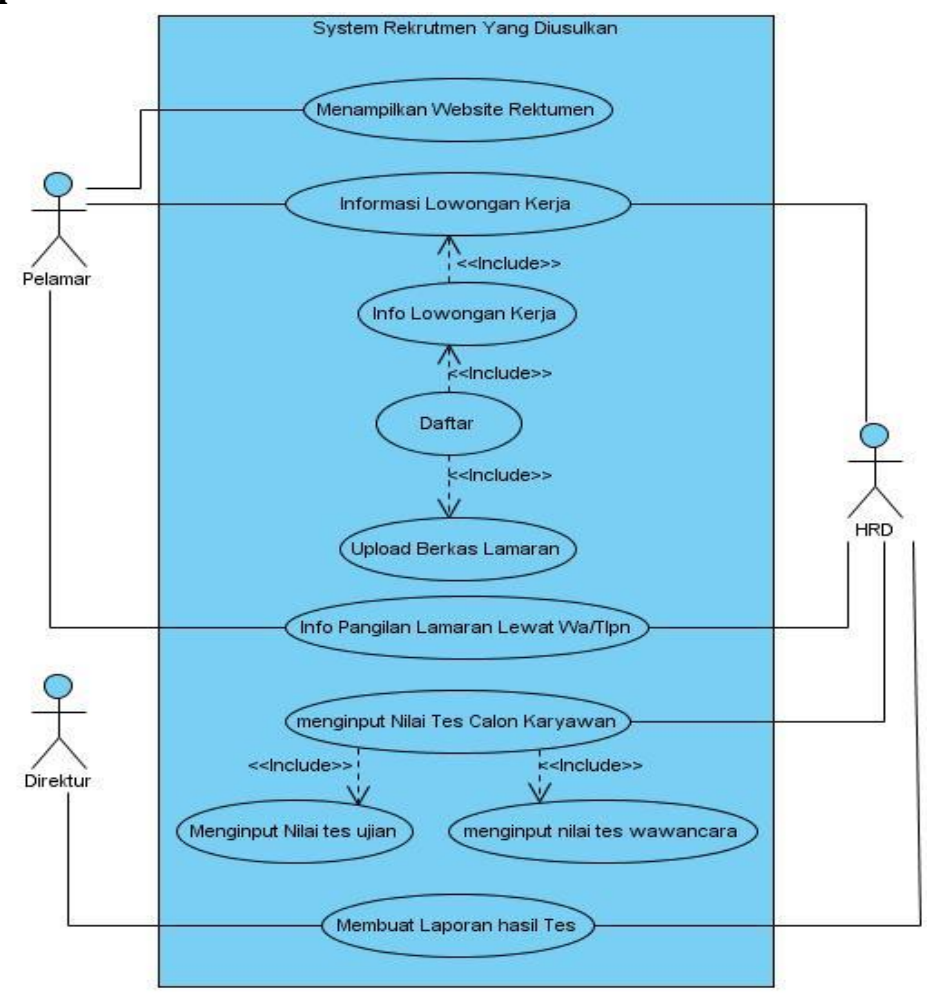

Gambar 1. Use Case Diagram

Gambar diatas berisi:

Pelamar membuka website rekrutmen untuk melihat informasi lowongan kerja yang tersedia, kemudian pelamar melakukan registrasi terlebih dahulu untuk bisa masuk ke website dan mendaftar lowongan kerja sesuai dengan posisi yang tersedia; pelamar mengunggah berkas lamaran sesuai dengan berkas yang dipersyaratkan; HRD akan memberi tahu pelamar melalui WA / telepon untuk tes panggilan; pelamar mengikuti serangkaian tes; HRD menginput hasil nilai pelamar; kemudian Direktur membuat laporan hasil Tes pelamar.

\section{Sequence Diagram}

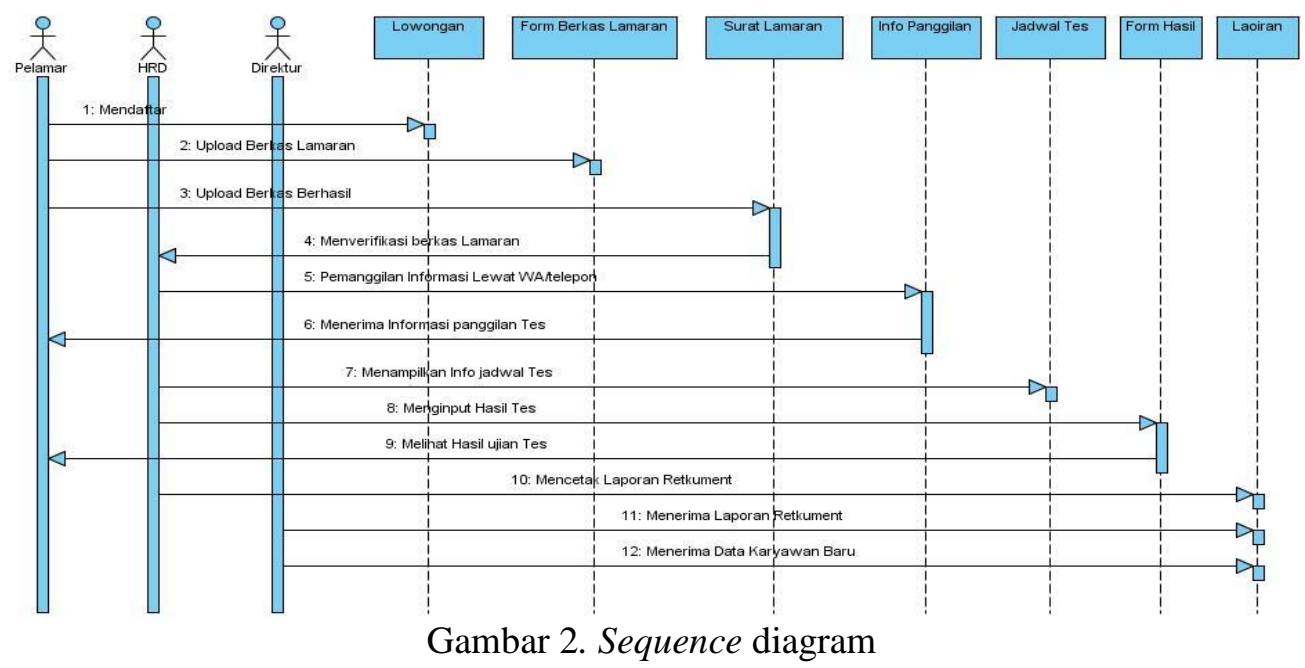


Gambar diatas berisikan :

Tiga actor terdiri dari: Pelamar, HRD, dan Direktur; tujuh Lifelines terdiri dari: Lowongan, form Berkas Lamaran, surat lamaran, info panggilan, jadwal tes, form Hasil dan Laporan; dua belas Message dalam memberikan informasi terkait gambaran tentang kegiatan yang sedang berlangsung yang dilakukan oleh aktor.

\section{Class Diagram}

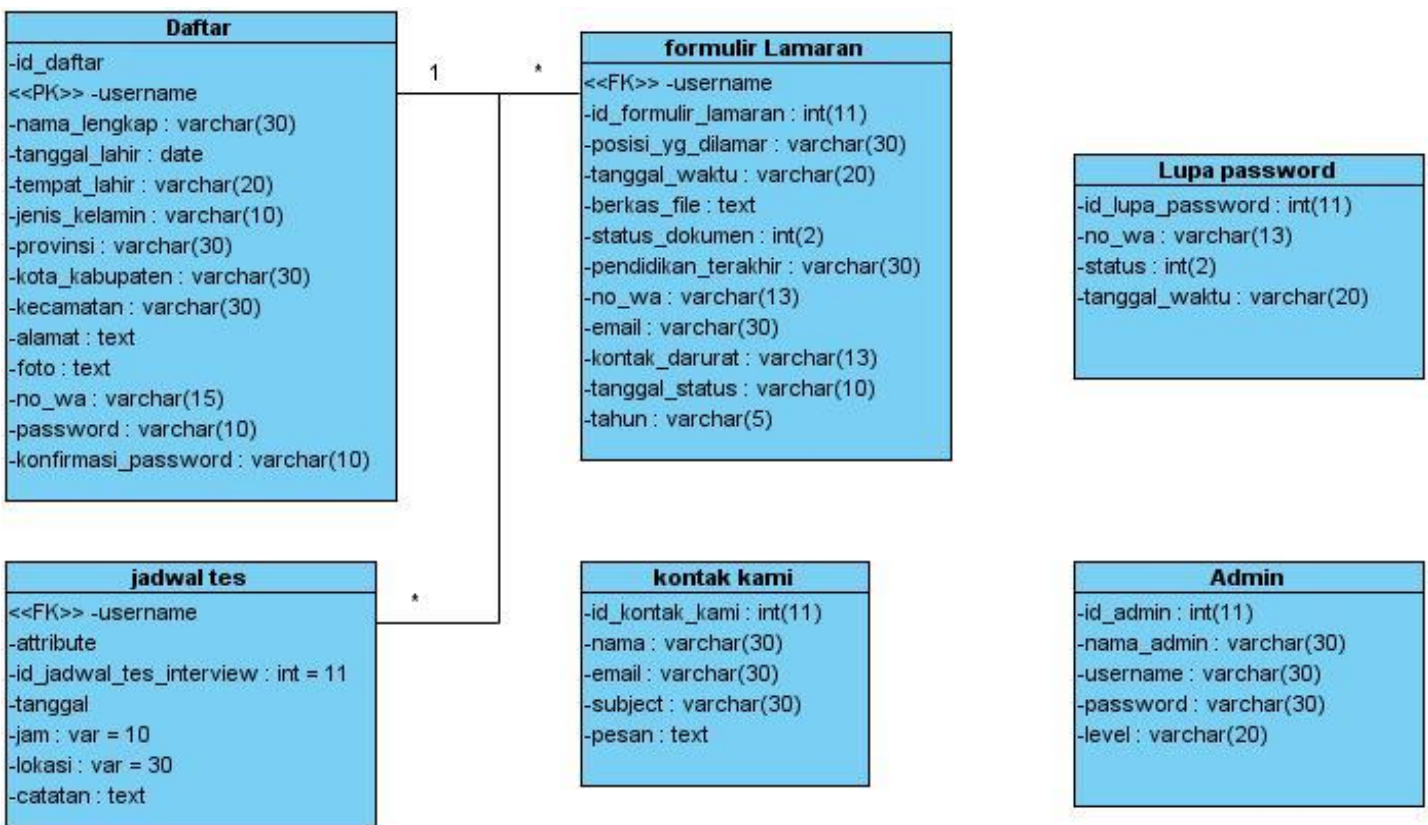

\begin{tabular}{|l|}
\hline \multicolumn{1}{|c|}{ Lowongan kerja } \\
\hline -id_lowongan_kerja : int(11) \\
-tanggal_ditayangkan \\
-tanggal_detlen \\
-posisi_yg_dibutuhkan : varchar(50) \\
-deskripsi_pekerjaan : text \\
-persyaratan1 : varchar(100) \\
-persyaratan2 : varchar(100) \\
-persyaratan3 : varchar(100) \\
-persyaratan4 : varchar(100) \\
-persyaratan5: varchar(100) \\
-persyaratan6 : varchar(100) \\
-persyaratan7 : varchar(100) \\
-persyaratan8 : varchar(100) \\
-tingkat_perkerjaan : varchar(50) \\
-kualifikasi : text \\
-pengalaman_kerja : varchar(10) \\
-jenis_pekerjaan ; varchar(20) \\
-spesialisasi_pekerjaan : varchar(30) \\
-tampilkan: int(2) \\
\hline
\end{tabular}

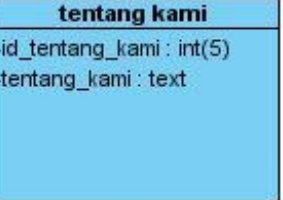

Gambar 3. Class Diagram

Gambar diatas membahas tentang perancangan database yang menjelaskan tentang tabel-tabel database, spesifikasi database yang akan digunakan pada sistem yang dibangun. 


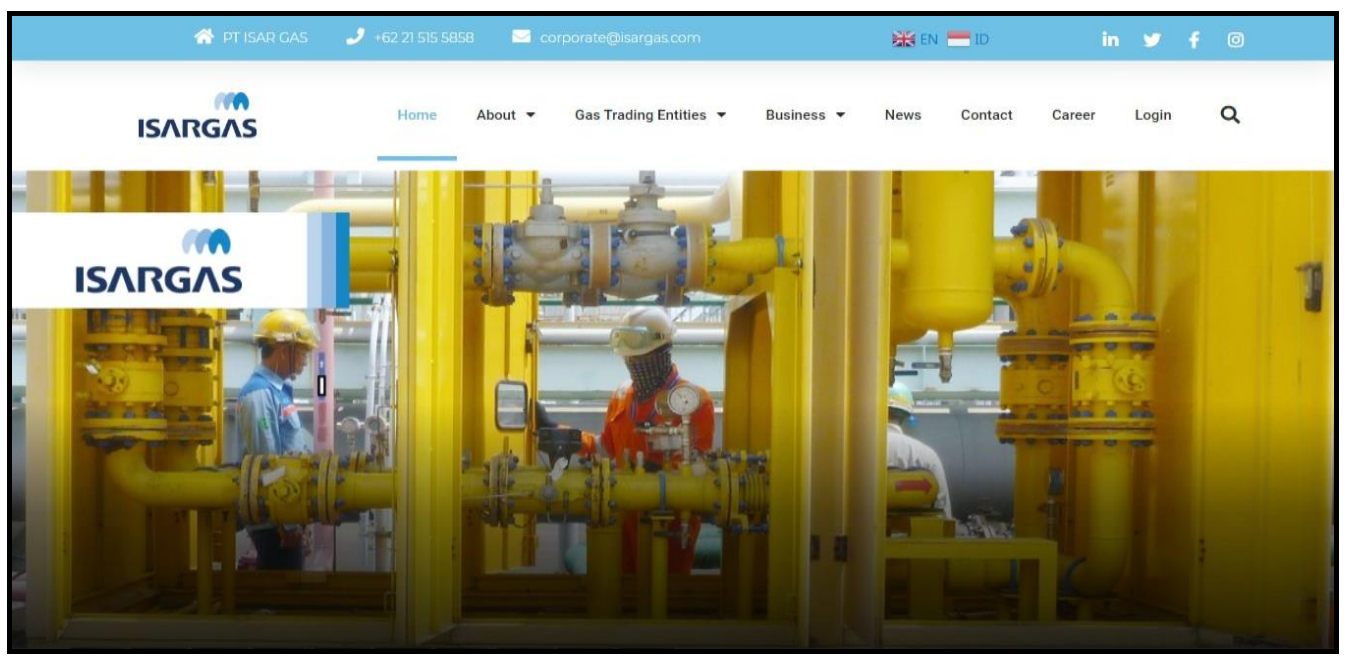

Gambar 4. Halaman awal website

Tampilan awal pada website Recruitment, pada menu ini terdapat menu login untuk masuk ke website, menu kontak berisi alamat dan kontak perusahaan, karir berisi informasi lowongan yang tersedia.

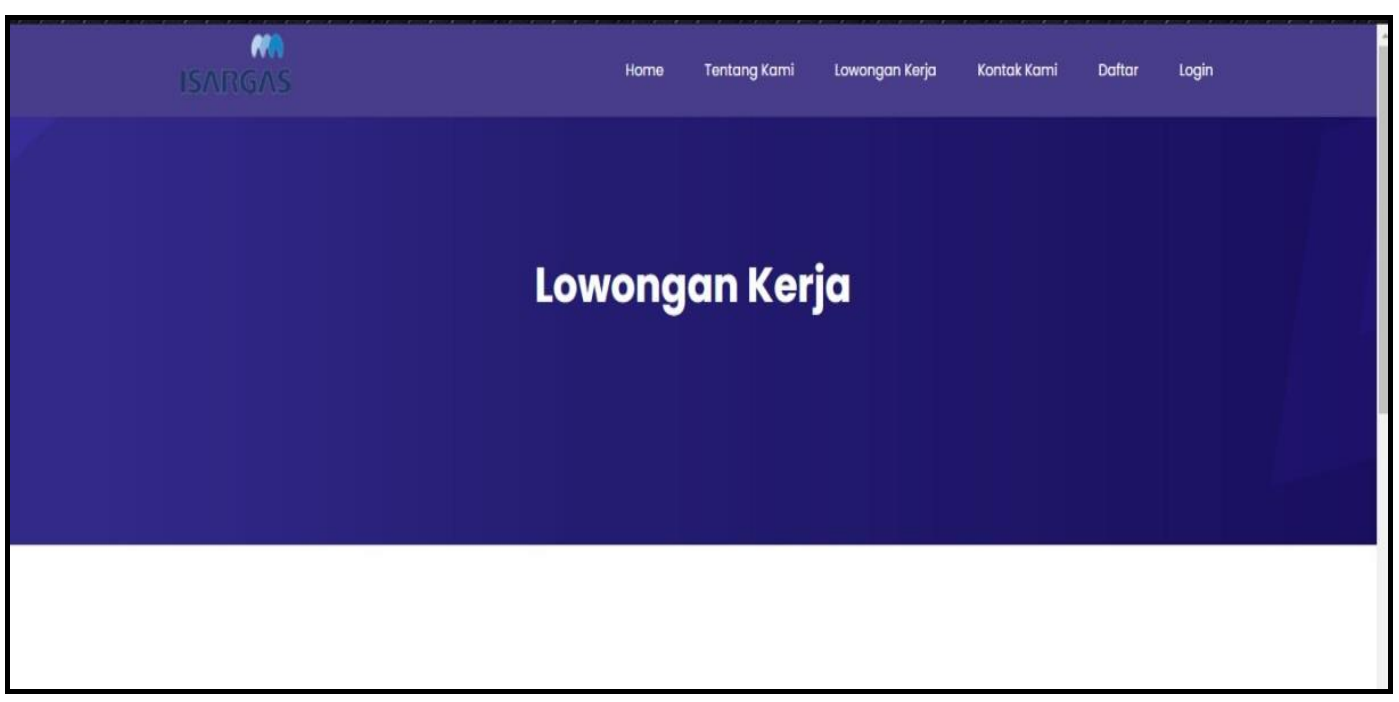

Gambar 5. Halaman Menu Lowongan Kerja pelamar.

Menampilkan menu home lowongan kerja untuk melanjutkan pendaftaran 


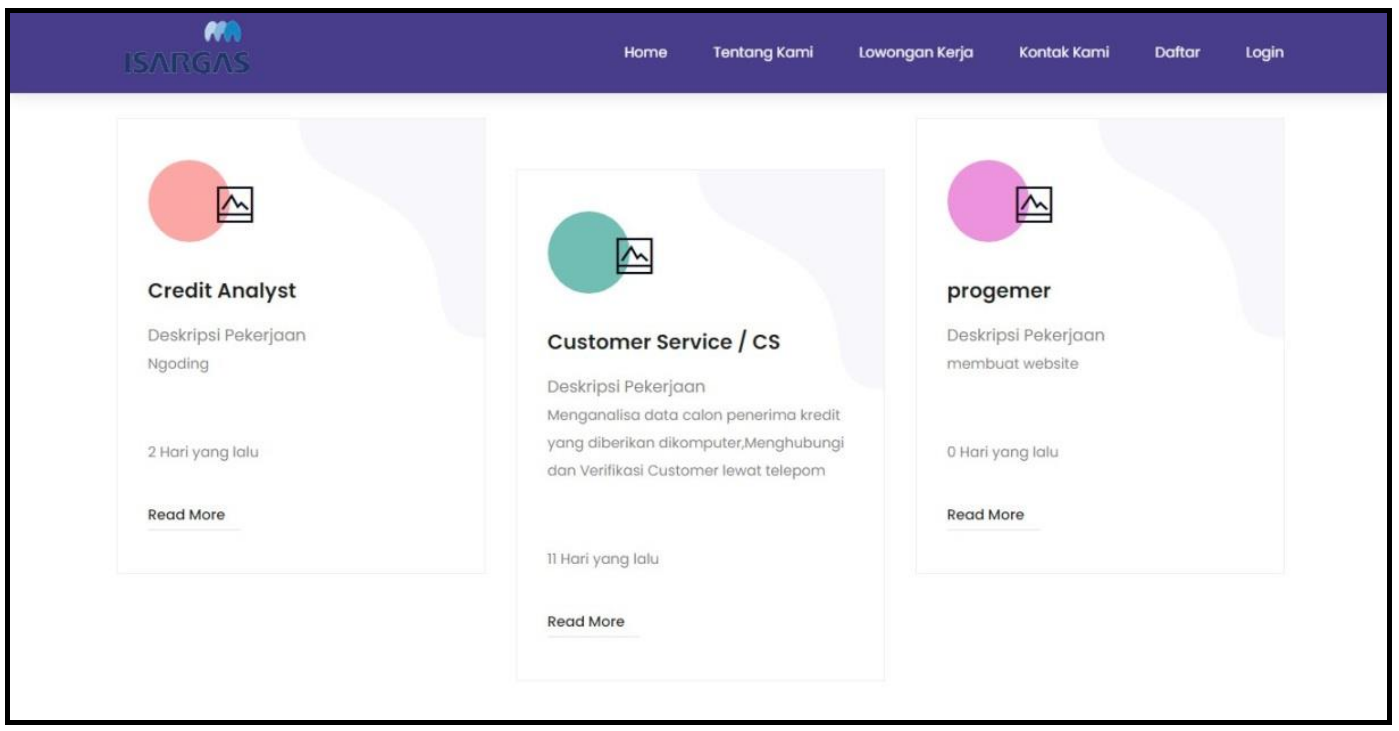

Gambar 6. Halaman Menu Detail Lowongan Kerja

Daftar detail lowongan kerja dan kemampuan.

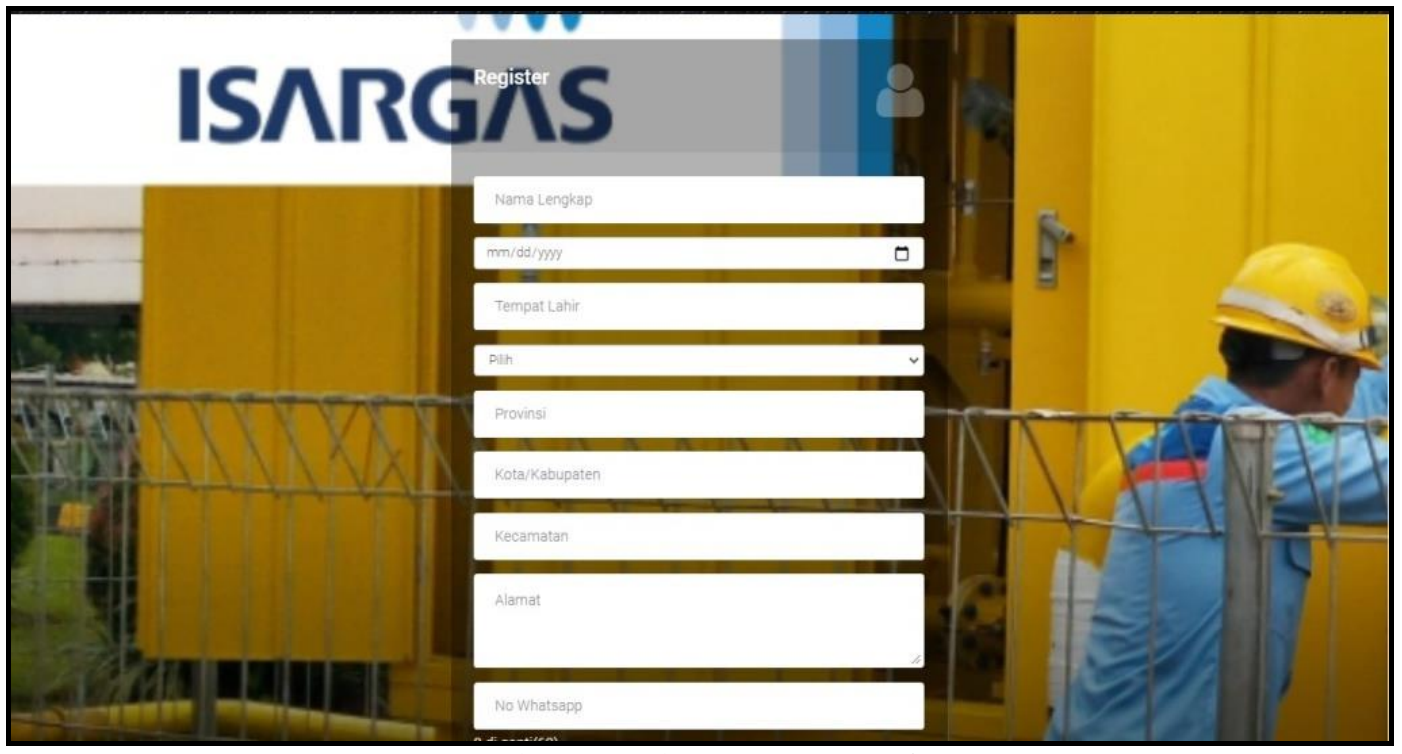

Gambar 7. Halaman Menu Daftar

Menampilkan menu register yang harus diselesaikan pelamar sebelum masuk ke menu selanjutnya untuk mengetahui ketersediaan update informasi lowongan yang dibutuhkan.. 


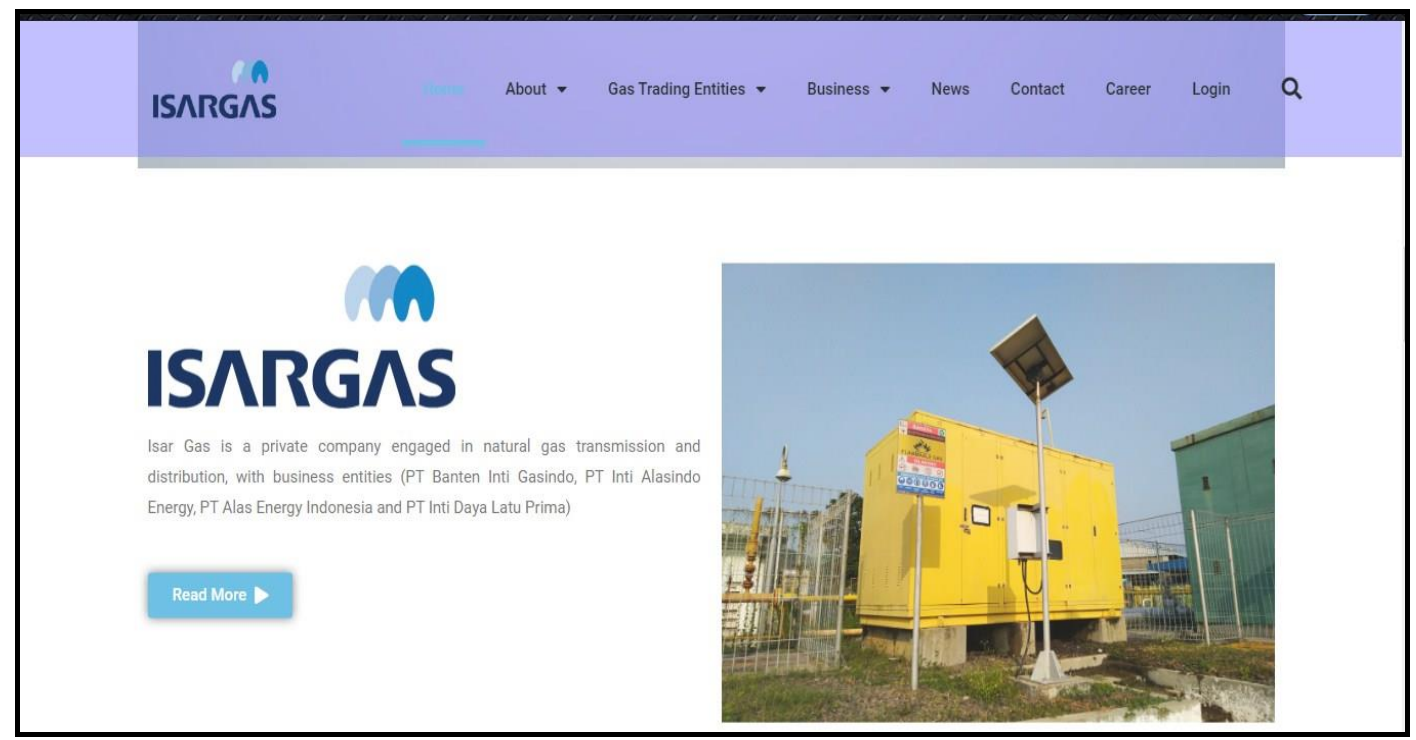

Gambar 8. Halaman Menu Profile Perusahaan

Menampilkan sekilas Profil Perusahaan PT.Isargas

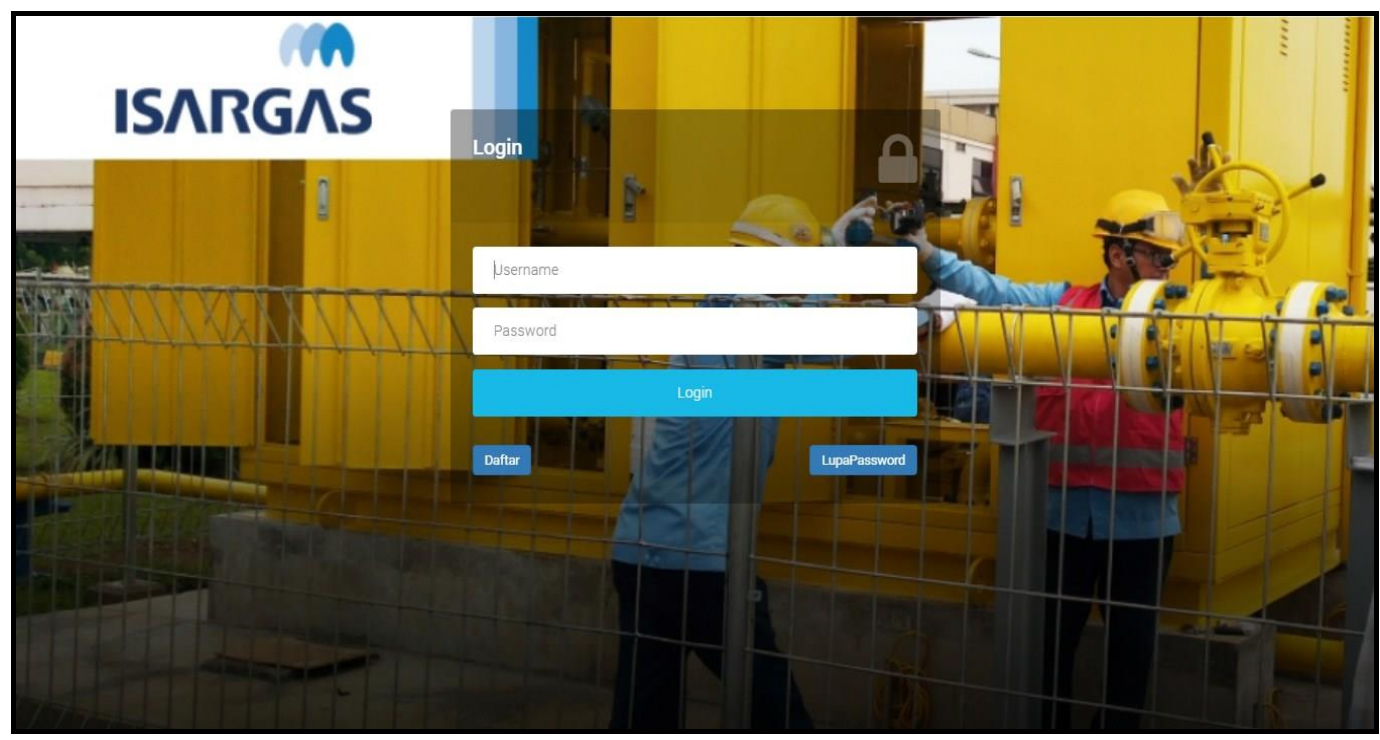

Gambar 9. Halaman Login

Memasukkan isi login user dan password untuk Admin ditambah ketersediaan Peralatan Komputer Lab 


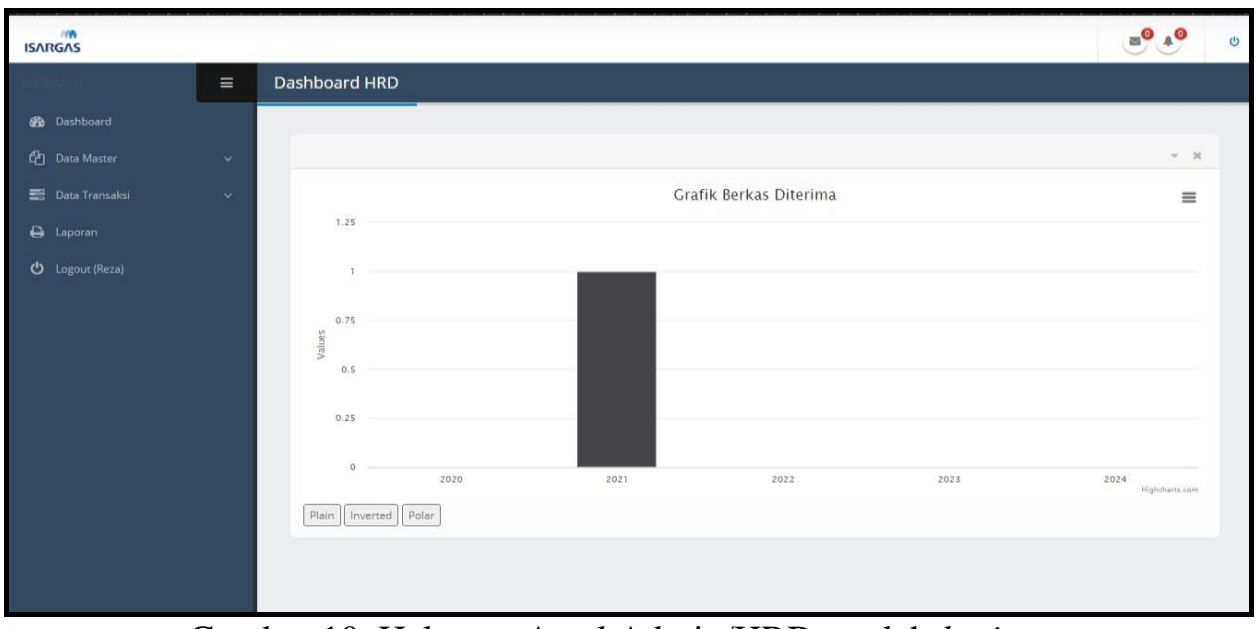

Gambar 10. Halaman Awal Admin/HRD setelah login

Halaman setelah login HRD menampilkan file grafik yang diterima

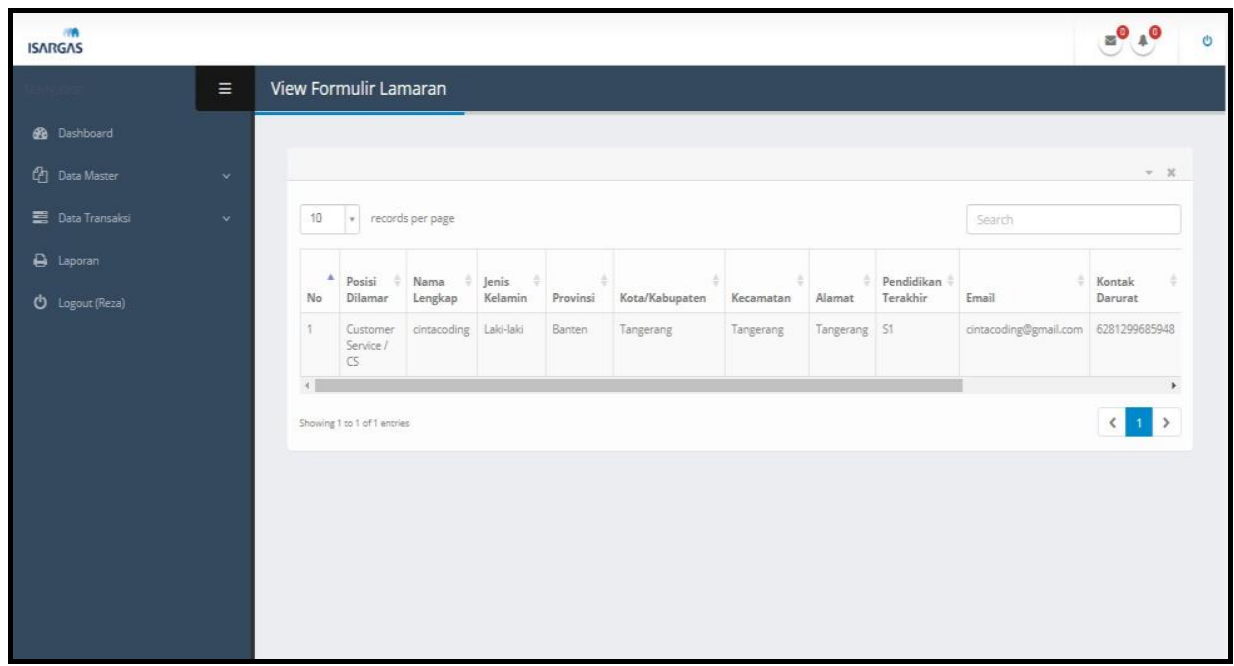

Gambar 11. Tampilan Halaman Data pelamar

Berisikan data-data pelamar pekerjaan dan kelengkapan berkas pelamar.

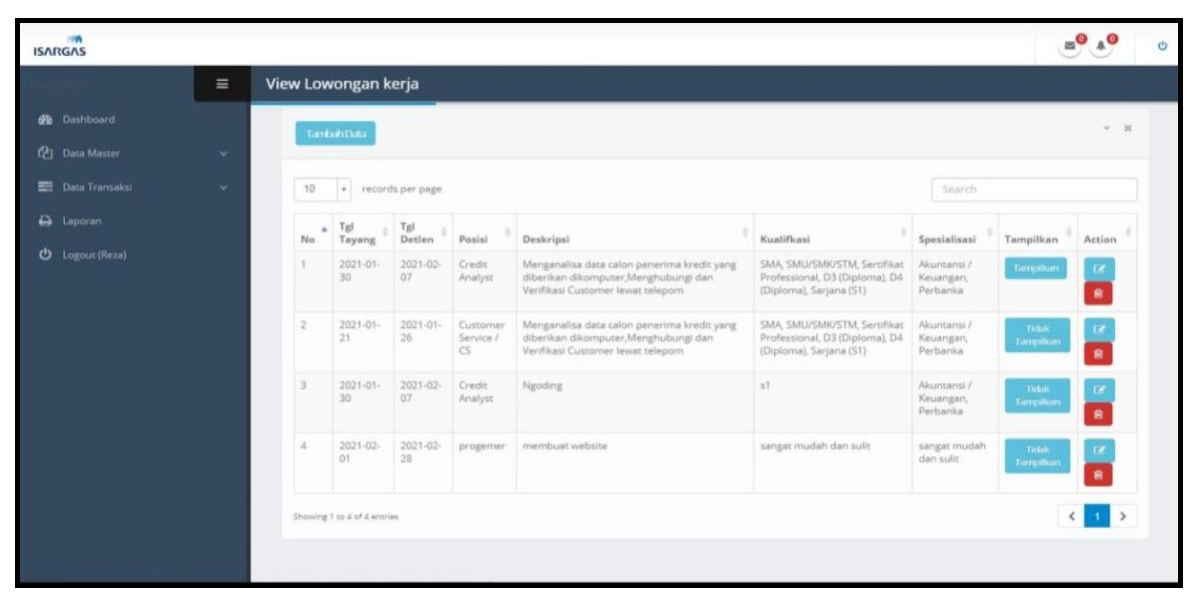

Gambar 12. View Lowongan Kerja

Kelola tampilan informasi lowongan kerja dan jadwal tayang dan dateline. 


\section{KESIMPULAN}

Proses penyebaran informasi lowongan pekerjaan yang berjalan saat ini masih sangat tidak kondusif dimana calon karyawan harus datang ke perusahaan untuk melihat wall board yang berisi informasi lowongan kerja, sehingga akan memakan banyak waktu dan kesalahan saat mendaftar calon karyawan, serta menumpuk file, serta dikhawatirkan terjadinya kehilangan file. Maka dibuatlah sistem aplikasi agar proses pengolahan data tidak terjadi kesalahan saat penginputan data dan akan tersimpan dengan aman file berisikan berkas lamaran pada sistem serta membantu calon karyawan untuk lebih mudah mendapatkan informasi lowongan dan melamar pekerjaan secara online.

\section{SARAN}

Disarankan agar Sistem Informasi Recruitment Karyawan untuk PT.Isargas yang telah dibuat ini dapat dikembangkan lagi sesuai kebutuhan perusahaan dan agar sistem ini dapat terus digunakan sehingga bermanfaat untuk PT.Isargas.

\section{DAFTAR PUSTAKA}

[1] Bairizki, A. 2020. Manajemen Sumber Daya Manusia (Tinjauan Strategis Berbasis Kompetensi) Jilid II. Surabaya : Pustaka Aksara

[2] Zamzami, F., Nusa, N.D., \& Faiz, I.A. 2021. Sistem Informasi Akuntansi. Yogyakarta : Gadjah Mada University Press

[3] Siregar, R.T dkk. 2020. Manajemen Sumber Daya Manusia Dalam Organisasi. Medan : Yayasan Kita Menulis

[4] Widyastuti, I., \& Sulistyorini, S. 2020. E-Recruitment Karyawan Berbasis Web Sebagai Upaya Meningkatkan Efisiensi Seleksi Penerimaan Karyawan Baru. Aksara Public, 4(4), 201-211.

[5] Yanto, A.B.H., Fauzi, A., \& Jariyah, F.A. 2018. Sistem Informasi E-Recruitment Karyawan Berbasis Web Pada PT. Jasa Swadayautama (Jayatama). Jurnal Teknologi Informatika dan Komputer, 4(2), 1-6

[6] Hapsari, P., \& Purwatiningtyas. 2017. Sistem Informasi Penerimaan Karyawan Berbasis Web Pada Brt Trans Semarang. Prosiding SINTAK, 299-306 